\title{
Social and gender variation in the prevalence, presentation and general practitioner provisional diagnosis of chest pain
}

\author{
Helen Richards, Alex McConnachie, Caroline Morrison, Keith Murray, Graham Watt
}

\begin{abstract}
Objectives-To describe the prevalence of Rose angina and non-exertional chest pain in men and women in socioeconomically contrasting areas; to describe the proportions of men and women who present with the symptom of chest pain and who receive a provisional general practitioner diagnosis of coronary heart disease; to assess the effects of gender and deprivation.
\end{abstract}

Design-Two random general population samples in socially contrasting areas were surveyed using the Rose angina questionnaire: the case notes of people identified with chest pain were reviewed.

Setting-Glasgow conurbation.

Participants-1107 men and women, aged 45-64, with chest pain.

Outcome measures-Prevalence of Rose angina and non-exertional chest pain; the proportions who had presented with chest pain and received a general practitioner's provisional diagnosis of coronary heart disease.

Results-There was no difference between social groups in the prevalence of all chest pain but a greater proportion of those in deprived groups had Rose angina and a greater proportion of these had the more severe grade. The proportion of people who had presented with chest pain was higher among socioeconomically deprived groups but there was no difference in the proportions receiving a general practitioner provisional diagnosis of coronary heart disease. Men were more likely to present with chest pain than women and were more likely to receive a provisional general practitioner diagnosis of coronary heart disease.

Conclusions-No evidence was found of social differences in patient presentation or general practitioner diagnosis that might explain reported variations in uptake of cardiology services. In contrast, gender variation may originate in part from differences in patient presentation and general practitioner diagnosis. Further investigation of socioeconomic variations in uptake of cardiology services should focus later in the care pathway, on general practitioner referral patterns and clinical decisions taken in secondary care. (F Epidemiol Community Health 2000;54:714-718)
Research in the United Kingdom shows that rates of uptake of coronary angiography and cardiac surgery are not commensurate with need, as measured by coronary heart disease prevalence $^{1}$ or mortality. ${ }^{2}$ A study based on coronary heart disease prevalence ${ }^{1}$ showed that patients in affluent areas with Rose angina were more likely to undergo coronary revascularisation than those in socially deprived areas. A Glasgow study that used mortality as a proxy for need demonstrated a relative excess of coronary angiography in patients from more affluent areas (Kesson E, personal communication). More recently, in Scotland, routine hospital admission data have demonstrated that socioeconomic deprivation and female gender ${ }^{3}$ are associated with relatively low rates of angiography and coronary artery bypass grafting. Another study based on routine data showed no gender difference in access to hospital, but after admission, men were more likely to receive cardiological investigations and treatment. ${ }^{4}$ This gender variation was confirmed in a large cross sectional study ${ }^{5}$ in which, after controlling for disease severity and comorbidity, it was found that women with coronary heart disease were less likely than men to undergo cardiac surgery.

Most studies reporting variations in access to hospital services have focused on processes occurring in secondary care. It is unclear whether such variations arise from decisions made by hospital doctors, general practitioners or patients. One exception was a study based on self report by angina patients of general practitioner referral for investigations. ${ }^{6}$ This showed that for five types of cardiac investigation, $59 \%$ of men with angina were referred compared with $37 \%$ of women.

Here, we describe the prevalence of Rose angina and non-exertional chest pain in two socially contrasting areas of Glasgow, where rates of coronary coronary angiography have been observed to be higher or lower than expected according to morbidity-based measure of need, in affluent and deprived areas respectively. ${ }^{3}$ We then compare the proportions of men and women with Rose angina and nonexertional chest pain who presented the symptom, and the proportion of those presenting to a general practitioner who received a provisional diagnosis of coronary heart disease.

\section{Methods}

POPULATIONS

The socioeconomically deprived population was the study population of surveys 3 and 4 of the Glasgow MONICA project, ${ }^{7}$ in Glasgow 
north of the Clyde, an area of severe socioeconomic deprivation, where $70 \%$ of the residents live in postcode sectors associated with Carstairs deprivation catgories 6 and 7 . We used the methods of the MONICA study to investigate an adjacent, affluent population, where $80 \%$ of the residents live in Carstairs deprivation categories 1 and 2 . As there was a degree of overlap in deprivation levels between the two populations, the data from the two areas were combined, with each subject classified by the Carstairs/Morris deprivation category ${ }^{8}$ of their postcode sector (1 to 7 , where 1 is affluent). Deprivation was treated as a 3 level variable because this classification system provided adequate and comparable numbers in each category and seemed appropriate in an area with unusually wide contrasts in socioeconomic status. The standardised mortality rates for people age 45-64 with coronary heart disease in the deprived and affluent populations, based on the 1991 census are 140 and 57 respectively (Womersley J, personal communication).

In the MONICA surveys, 57 general practitioners in Glasgow north of the Clyde were randomly selected and all registered patients aged 25-64 were identified using the Community Health Index. ${ }^{9}$ A stratified random sample of these patients was sent the Rose angina questionnaire $^{10}$ to obtain approximately 200 respondents in each 10 year age/sex group. Here, we re-contacted 50 of the original general practitioners and seven who had replaced retired partners and included all respondents aged 45-64 with chest pain.

We set out to identify a similar number of cases of chest pain from the affluent area. Our sample size was calculated by assuming that in the two geographical areas, angina prevalence is proportional to the standardised mortality rates for coronary heart disease. A fifty per cent stratified random sample of people aged 45-64, registered with all 24 general practitioners practising in the affluent area was generated using SPSS for Windows and surveyed using the Rose angina questionnaire $(n=5033)$.

General practices were classified by the proportion of patients attracting deprivation payments ${ }^{11}$ : "affluent" (less than 20\%) and "deprived" (20\% or more).

CASE DEFINITIONS

The Rose angina questionnaire distinguishes "non-exertional chest pain" (mainly respiratory, dyspepsia and muscular) from Rose angina, which is itself subdivided into two grades of severity (grade I: chest pain on walking up hill; grade II: chest pain on the level). Here, we included people with non-exertional chest pain and Rose angina, and refer to the combined category as "all chest pain". Altogether 196 cases of probable myocardial infarction (severe central chest pain lasting for more than 30 minutes) were excluded because of the different management and clinical course of this category of chest pain. ${ }^{12}$ In addition to the Rose angina questionnaire categories, we refer to the general practitioner's "provisional diagnosis". We acknowledge that Rose angina and subjective symptoms are imperfect indicators of the coronary heart disease prevalence.

CASE NOTE RETRIEVAL

General practitioner case notes were searched to establish (a) whether subjects with nonexertional chest pain or Rose angina had presented with chest pain before the surveys (since 1986) and (b) the general practitioner's provisional diagnosis (coronary heart disease/ other-clearly stated or implied). All data were collected by HR, using a pre-piloted check list.

Ethical approval for all parts of the study was obtained from local research ethics committees.

\section{ANALYSIS}

Statistical analyses were performed using logistic regression models, fitted by SPSS version 6.1.3. The proportions of cases of all chest pain with Rose angina and of Rose angina meeting the more severe grade were modelled with age group (a 4 level categorical variable: 45-49, 50-54, 55-59, 60-64), deprivation category (a 3 level categorical variable: $1-2,3-5$ and $6-7$ ) and gender, as dependent variables. The probability of presenting was modelled with deprivation category, chest pain type (nonexertional chest pain/Rose angina grades I/II) and gender. The same predictors were used to model provisional diagnosis (coronary heart disease/other). An alternative model, with practice deprivation type (affluent/deprived) instead of patient deprivation category was also used. Significance of model terms is expressed by the Wald $\chi^{2}$ statistic. Effect estimates are reported as odds ratios with $95 \%$ confidence intervals.

\section{Results}

PRACTICES

Some $96.5 \%$ of the MONICA study general practitioners and $88 \%$ in the affluent area allowed access to case notes. The MONICA practices were smaller than the affluent practices, with mean list sizes and mean numbers of partners of 4537 and 3.2, and 6700 and 4.2 respectively. All practices in the affluent area were affluent practices and $90.0 \%$ of those in the deprived area were deprived practices.

RESPONSE RATES

In the affluent population, 4937 of the 5033 questionnaires reached the addressee and 3232 $(64.2 \%)$ were returned. Some 161 cases were excluded because their true dates of birth fell outside the inclusion criteria and 196 because they were cases of possible myocardial infarction, leaving 2875 cases for analysis. Of these, $660(23.0 \%)$ reported chest pain and we reviewed the case notes of $593(89.8 \%)$. The response rate for people aged $45-64$ in the original MONICA survey was $70.1 \%$. Of the 1778 MONICA respondents, $447(25.1 \%)$ had chest pain and the case notes of 399 (89.3\%) were reviewed.

Of the 992 case notes reviewed, it was clear whether presentation had occurred in 966 cases $(97.4 \%)$. Of the 454 cases presenting to a 
Table 1 Prevalence of Rose angina and non-exertional chest pain; Rose angina as a proportion of all chest pain and grade II Rose angina as a proportion of all Rose angina $(n=1092)$

\begin{tabular}{|c|c|c|c|c|c|c|c|c|c|c|c|c|}
\hline \multirow[b]{3}{*}{$\begin{array}{l}\text { Agel } \\
\text { gender }\end{array}$} & \multicolumn{12}{|c|}{ Deprivation category } \\
\hline & \multicolumn{4}{|l|}{1,2} & \multicolumn{4}{|l|}{$3,4,5$} & \multicolumn{4}{|l|}{6,7} \\
\hline & $\begin{array}{l}\text { Rose } \\
\text { angina \% } \\
\text { (n) }\end{array}$ & $\begin{array}{l}\text { Non- } \\
\text { exertional } \\
\text { chest pain } \\
\%(n)\end{array}$ & $\begin{array}{l}\text { Rose } \\
\text { angina/ all } \\
\text { chest pain } \\
\%(n)\end{array}$ & $\begin{array}{l}\text { Grade II/ } \\
\text { all Rose } \\
\text { angina \% } \\
(n)\end{array}$ & $\begin{array}{l}\text { Rose } \\
\text { angina \% } \\
\text { (n) }\end{array}$ & $\begin{array}{l}\text { Non- } \\
\text { exertional } \\
\text { chest pain } \\
\%(n)\end{array}$ & $\begin{array}{l}\text { Rose } \\
\text { angina/ all } \\
\text { chest pain } \\
\%(n)\end{array}$ & $\begin{array}{l}\text { Grade II/ } \\
\text { all Rose } \\
\text { angina \% } \\
(n)\end{array}$ & $\begin{array}{l}\text { Rose angina } \\
\%(n)\end{array}$ & $\begin{array}{l}\text { Non- } \\
\text { exertional } \\
\text { chest pain } \\
\%(n)\end{array}$ & $\begin{array}{l}\text { Rose } \\
\text { anginal all } \\
\text { chest pain } \\
\%(n)\end{array}$ & $\begin{array}{l}\text { Grade II/ } \\
\text { all Rose } \\
\text { angina } \% \\
(n)\end{array}$ \\
\hline \multicolumn{13}{|l|}{ Men } \\
\hline $45-49$ & $3.3(8)$ & $17.5(42)$ & $16.0(8)$ & $25.0(2)$ & $5.1(5)$ & $17.3(16)$ & $23.8(5)$ & $20.0(1)$ & $12.8(19)$ & $9.5(14)$ & $57.6(19)$ & $42.1(8)$ \\
\hline $50-54$ & $3.0(10)$ & $21.3(70)$ & $12.5(10)$ & $30.0(3)$ & $7.6(10)$ & $22.1(29)$ & $25.6(10)$ & $40.0(4)$ & $14.6(22)$ & $13.2(20)$ & $52.4(22)$ & 59.1 (13) \\
\hline $55-59$ & $5.8(16)$ & $16.7(46)$ & $25.8(16)$ & $25.0(4)$ & $10.9(11)$ & $13.9(12)$ & $47.8(11)$ & $36.4(4)$ & $20.6(33)$ & $4.7(8)$ & $80.5(33)$ & $40.0(14)$ \\
\hline $60-64$ & $7.5(22)$ & $15.0(44)$ & $33.3(22)$ & $31.8(7)$ & $9.6(11)$ & $16.5(19)$ & $36.7(11)$ & $18.2(2)$ & $20.9(32)$ & $6.5(10)$ & $76.2(32)$ & $34.4(11)$ \\
\hline $\begin{array}{l}\text { Total } \\
\text { Women }\end{array}$ & $4.9(56)$ & $17.7(202)$ & $21.7(56)$ & $28.6(16)$ & $8.3(37)$ & $17.0(76)$ & $32.7(37)$ & $29.7(11)$ & $17.0(106)$ & $8.4(52)$ & $67.1(106)$ & $42.6(46)$ \\
\hline $45-49$ & $6.8(21)$ & $12.2(38)$ & $35.6(21)$ & $9.5(2)$ & $8.6(11)$ & $9.4(11)$ & $50.0(11)$ & $36.4(4)$ & $18.8(30)$ & $7.5(12)$ & $71.4(30)$ & $50.0(15)$ \\
\hline $50-54$ & $3.9(15)$ & $15.4(60)$ & $20.0(15)$ & $6.7(1)$ & $14.0(22)$ & $17.8(18)$ & $55.0(22)$ & $50.0(11)$ & $13.0(22)$ & $4.8(8)$ & $73.3(22)$ & $40.1(9)$ \\
\hline $55-59$ & $8.7(31)$ & $12.4(44)$ & $41.3(31)$ & $19.4(6)$ & $10.8(14)$ & $13.0(17)$ & $45.2(14)$ & $35.7(5)$ & $21.4(31)$ & $6.9(10)$ & $75.6(31)$ & $35.5(11)$ \\
\hline $60-64$ & $7.9(23)$ & $13.8(44)$ & $34.3(23)$ & $17.4(4)$ & $15.2(21)$ & $13.8(19)$ & $52.5(21)$ & $28.6(6)$ & $12.9(24)$ & $9.1(17)$ & $58.5(24)$ & $37.5(9)$ \\
\hline Total & $6.6(90)$ & $13.5(186)$ & $32.6(90)$ & $14.4(13)$ & $12.3(68)$ & $12.2(65)$ & $51.1(68)$ & $38.2(26)$ & $16.2(107)$ & $7.1(47)$ & $69.6(107)$ & $41.1(44)$ \\
\hline
\end{tabular}

1092 (98.7\%) of the 1107 cases of chest pain were classifiable as Rose angina or non-exertional chest pain.

general practitioner, the provisional diagnosis was clear in $398(87.7 \%)$ cases and was similar in high and low deprivation practices.

PREVALENCE OF ALL CHEST PAIN AND ROSE ANGINA GRADES I AND II (TABLE 1)

The prevalence of Rose angina increased with age in both populations, was higher in women and higher in deprived areas. Non-exertional chest pain was reported more commonly in affluent areas.

The proportion of all chest pain cases classified as Rose angina was modelled as depending on age, gender and patient deprivation category. There was a significant deprivation effect $\left(\chi^{2}=127.00\right.$ on $\left.2 \mathrm{df}, \mathrm{p}<0.0001\right)$; relative to the most affluent group, the odds ratios for the intermediate and most deprived group were estimated as 2.00 (95\% CI 1.45, 2.75), p $<0.0001$ and 5.86 (4.31, 7.97), $\mathrm{p}<0.0001$ respectively. Gender was also significant; relative to men, the odds ratio for women was 1.62 $(1.25,2.10), \mathrm{p}=0.0003$.

The proportion of cases of Rose angina classified as grade II was associated with deprivation $\left(\chi^{2}=15.76, p=0.0004\right)$; relative to the most affluent group, the odds ratios for the intermediate and most deprived groups were estimated as $2.13(1.20,2.38), p=0.0099$ and
$2.70(1.65,4.40), \mathrm{p}=0.0001$ respectively. There was no relation with gender $(p=0.30)$.

PRESENTATION OF CHEST PAIN (TABLE 2)

The proportion of people who presented with chest pain was lower for non-exertional chest pain than for Rose angina and for cases of Rose angina, the proportion was lower for the less severe grade. Relative to non-exertional chest pain, the odds ratios for Rose angina grades I and II were $1.13(0.83,1.53) \mathrm{p}=0.49$ and 1.60 $(1.06,2.44) \mathrm{p}=0.03$ respectively (overall $\mathrm{p}=$ $0.086)$. The proportion of people presenting was positively associated with patient deprivation and male gender. Relative to the most affluent group, the odds ratios for the intermediate and most deprived groups were 1.41 (1.02, 1.96), $\mathrm{p}=0.040$ and $1.91(1.38,2.66)$, $\mathrm{p}=0.0001$ respectively. Relative to women, the odds ratio for men was $1.53(1.18,1.99), \mathrm{p}=$ 0.0013 .

PROVISIONAL DIAGNOSIS (TABLE 3)

The probability of receiving a provisional general practitioner diagnosis of coronary heart disease was positively associated with chest pain type and male gender. Relative to non-exertional chest pain, the odds ratios for Rose angina grades I and II were 2.75 (1.67, $4.52)$ and $3.4(1.87,6.16)$ respectively, $\mathrm{p}=$ 0.0001 . Compared with women, the odds ratio

Table 2 Presentation of chest pain and the proportion of cases presenting to a general practitioner who received a provisional diagnosis of coronary heart disease (CHD)

\begin{tabular}{|c|c|c|c|c|c|c|}
\hline & \multicolumn{6}{|l|}{ Deprivation category } \\
\hline & \multicolumn{2}{|l|}{1,2} & \multicolumn{2}{|l|}{$3,4,5$} & \multicolumn{2}{|l|}{6,7} \\
\hline & $\begin{array}{l}\text { proportion of cases } \\
\text { presenting, } \%(n)\end{array}$ & $\begin{array}{l}\text { proportion of those } \\
\text { presenting to GP who } \\
\text { received a provisional } \\
C H D \text { diagnosis \% (n) }\end{array}$ & $\begin{array}{l}\text { proportion of cases } \\
\text { presenting, } \%(n)\end{array}$ & $\begin{array}{l}\text { proportion of those } \\
\text { presenting to GP who } \\
\text { received a provisional } \\
C H D \text { diagnosis \% (n) }\end{array}$ & $\begin{array}{l}\text { proportion of cases } \\
\text { presenting, } \%(n)\end{array}$ & $\begin{array}{l}\text { proportion of those } \\
\text { presenting to GP who } \\
\text { received a provisional } \\
C H D \text { diagnosis \% (n) }\end{array}$ \\
\hline \multicolumn{7}{|l|}{ Men } \\
\hline Rose angina grade II & $75.0(9)$ & $71.4(5)$ & $70.0(7)$ & $66.7(4)$ & $68.4(26)$ & $66.7(12)$ \\
\hline Rose angina grade I & $54.3(19)$ & $66.7(10)$ & $68.0(17)$ & $50.0(7)$ & $67.3(37)$ & $60.7(17)$ \\
\hline Non-exertional chest pain & $50.3(90)$ & $38.6(27)$ & $57.7(37)$ & $57.1(16)$ & $61.7(29)$ & $39.1(9)$ \\
\hline $\begin{array}{l}\text { Total } \\
\text { Women }\end{array}$ & $52.2(118)$ & $45.1(42)$ & $61.6(61)$ & $56.3(27)$ & $65.7(92)$ & $55.1(38)$ \\
\hline Rose angina grade II & $61.5(8)$ & $87.5(7)$ & $66.7(16)$ & $42.9(6)$ & $60.5(23)$ & $68.4(13)$ \\
\hline Rose angina grade I & $36.6(26)$ & $52.6(10)$ & $40.0(14)$ & $60.0(6)$ & $67.8(40)$ & $64.7(22)$ \\
\hline Non-exertional chest pain & $38.8(62)$ & $13.3(6)$ & $48.3(29)$ & $53.8(14)$ & $58.5(24)$ & $14.3(2)$ \\
\hline Total & $39.3(96)$ & $30.4(23)$ & $49.6(59)$ & $52.0(26)$ & $63.0(87)$ & $55.2(37)$ \\
\hline
\end{tabular}

Whether or not presentation had occurred was clear in 966 (97.4\%) of the 1107 classified cases of chest pain. The provisional GP diagnosis was clear in 398 (87.7\%) of the 454 cases who presented to a GP. 
Table 3 General practitioner provisional cardiac diagnosis by practice deprivation type

\begin{tabular}{lll}
\hline & \multicolumn{2}{c}{$\begin{array}{l}\text { Proportion of cases with a } \\
\text { provisional GP CHD diagnosis }\end{array}$} \\
\cline { 2 - 3 } & $\begin{array}{l}\text { Affluent } \\
\text { practices, \% (n) }\end{array}$ & $\begin{array}{l}\text { Deprived } \\
\text { practices, \% (n) }\end{array}$ \\
\hline Men & & \\
Rose angina grade 2 & $72.7(8)$ & $68.4(13)$ \\
Rose angina grade 1 & $65.0(13)$ & $57.1(20)$ \\
Non-exertional chest pain & $43.6(41)$ & $40.7(11)$ \\
Total & $49.6(62)$ & $54.3(44)$ \\
$\begin{array}{l}\text { Romen } \\
\text { Rose angina grade 2 }\end{array}$ & $58.8(10)$ & $66.7(16)$ \\
Non-exertional chest pain & $61.5(16)$ & $59.5(22)$ \\
Total & $27.2(17)$ & $21.7(5)$ \\
\hline
\end{tabular}

for men was $1.53(1.00,2.32), \mathrm{p}=0.048$. There was no relation with patient deprivation $\left(\chi^{2}=3.12, \mathrm{p}=0.21\right)$ or practice deprivation level $\left(\chi^{2}=3.90, p=0.36\right)$.

\section{Discussion}

Using the Rose angina questionnaire, we identified cases of Rose angina and non-exertional chest pain in two contiguous, socially contrasting populations that use the same major hospitals for cardiology referrals. By searching case notes, we ascertained the proportions of these cases who presented with the symptom of chest pain, and of those who had presented to the general practitioner, the proportion who were provisionally diagnosed as having coronary heart disease. Regardless of its accuracy, the general practitioner's provisional diagnosis is important in determining whether a patient is referred for further investigation.

The Rose angina questionnaire is an epidemiological screening instrument ${ }^{10}$ and not a diagnostic test. ${ }^{13}$ It was designed using a male population $^{14}$ and its validation is complicated by the lack of a gold standard for angina. ${ }^{15}$ Previous studies, like ours, have demonstrated similar prevalences of Rose angina in men and women despite the known excess of coronary heart disease in men. ${ }^{7}$ This may be because a higher proportion of women with chest pain turn out to have normal coronary arteries on angiography, ${ }^{16}$ or because of gender differences in response to the questionnaire. Despite the limitations of the Rose angina questionnaire, its categories of non-exertional chest pain and Rose angina grades I and II are associated with progressive increases in risk of major cardiac events ${ }^{13}$ in men and with coronary heart disease mortality in men and women. ${ }^{12}$ Its use was justified because of the need to identify cases of chest pain in the community.

PATIENT DEPRIVATION

Use of an area measure of deprivation ${ }^{8}$ to classify people was justified in this study because the postcode sectors used are socially homogeneous and the possibility of misclassifying people (which occurs when there is wide social variation within a small geographical area) was low.

A wide range of prevalences of Rose angina (grades I and II) and non-exertional chest pain have been previously reported in Scotland, ${ }^{17}$ but the relative proportions of chest pain types were not reported in these studies, nor were
KEY POINTS

- There was no difference in the prevalence of chest pain between people living in affluent and socioeconomically deprived areas. But in areas of socioeconomic deprivation, more cases of chest pain were classified as Rose angina and more Rose angina cases were classified as more severe.

- People with chest pain from socioeconomically deprived areas were more likely to present with the symptom than people from affluent areas, but there was no difference in the proportions of those presenting to their general practitioner who were provisionally diagnosed as having coronary heart disease.

- Men with chest pain were more likely than women to present with chest pain, and of those presenting to a general practitioner a greater proportion of men received a diagnosis of coronary heart disease.

- Decisions made by patients and general practitioners at the point of entry to medical care do not seem to explain reported socioeconomic variations in uptake of cardiology services. In contrast, gender variation in uptake may be explained by lower rates of presentation and diagnosis.

associations with social deprivation and gender. Here, we found a similar prevalence of all chest pain in affluent and deprived areas, but in the deprived areas a higher prevalence of Rose angina. Of these cases, a higher proportion was grade II. While the excess of angina in the deprived areas is likely to be a true reflection of disease prevalence, ${ }^{18}{ }^{19}$ the apparent excess of non-exertional chest pain in affluent areas may be artefactual ${ }^{20}$ : the Rose angina questionnaire classifies respondents who report "nonexertional chest pain" and "Rose angina" as "Rose angina only", and because comorbidity ${ }^{21}$ is commoner in deprived areas, more nonexertional chest pain will go unrecorded. There may also be social variation in responses to the questionnaire.

Compared with those in affluent areas, a greater proportion of people with chest pain from the deprived areas presented their symptom. This finding may be specific to chest pain or it may reflect of the general higher use of primary care services in deprived areas. ${ }^{22}$ Of men with grade II Rose angina, a greater, albeit statistically non-significant proportion presented from the affluent area. This suggests that the relation between high consultation rates and deprivation is weaker for severe symptoms that are less open to individual interpretation.

Patient's social status can influence general practitioners' diagnostic and management decision $\mathrm{s}^{23}$ but in patients presenting to a general practitioner we found no link between the proportion who received a provisional diagnosis of coronary heart disease and either the patient's deprivation status or the practice deprivation level. 
GENDER

Rose angina prevalence was higher in women in the most affluent group but not in the most deprived group. In women, Rose angina comprised a greater proportion of all chest pain than in men. This is unlikely to represent a greater prevalence of angina in women, given the well known excess of coronary heart disease in men. ${ }^{18}$ It might be explained by a relative excess of non-exertional chest pain in men, or gender differences in the tendency to report Rose angina and/or non-exertional chest pain.

After controlling for deprivation and chest pain type, men were more likely to present to a general practitioner than women. This may be explained by the fact that the dominant public health and media images of heart disease victims have been male, ${ }^{24}$ causing women to disregard chest pain or downplay their susceptibility to heart disease. ${ }^{25}$ The general female excess in general practitioner consultation rates $^{26}$ has been shown to be smaller for serious symptoms. ${ }^{27}$

After controlling for chest pain type, a greater proportion of men received a provisional general practitioner diagnosis of coronary heart disease than women, which may be considered appropriate in view of the fact that the condition is commoner in men. ${ }^{6}$ It may also reflect a belief among general practitioners that men are more likely to benefit from invasive investigations and treatment and therefore that it is more important to make a diagnosis of coronary heart disease in men. ${ }^{28}$

This study is unusual in that it tackles the problem of access to health services at an early stage in the care pathway, before symptoms have been sorted into specific diseases and before sufferers have become patients. Its main limitation is that general practitioner case notes (which often include non-standard abbreviations, incomplete summaries and examples of poor legibility ${ }^{29}$ ) are poorly suited to the collection of research data. There was no evidence however that the extent of this problem varied between deprived and non-deprived practices.

In conclusion, we found that the proportion of all chest pain that was angina, and the proportion of Rose angina that was grade II increased with increasing levels of socioeconomic deprivation. We found evidence for higher rates of presentation in the affluent area, and no socioeconomic differences in the rates of general practitioner diagnosis of coronary heart disease. After controlling for socioeconomic deprivation, men were more likely to present with chest pain than women and more likely to receive a provisional general practitioner diagnosis of coronary heart disease. Future research on inequities in access to cardiology services should focus on general practitioner referral decisions for people with chest pain and on clinical decisions made in hospitals. Qualitative work is also needed to explain why women are less likely to present with chest pain, and less likely to be diagnosed by general practitioners as having coronary heart disease.
We would like to thank Dr Margaret Reid for her advice, Karen Kane for her secretarial work, and the general practices and respondents for their cooperation.

Funding: funded by the Wellcome Trust.

Conflicts of interest: none.

1 Payne JN, Saul C. Variations in use of cardiology services in a health authority: comparison of coronary artery revascuarisation rates with prevalence of angina and coronary mortality. BMF 1997;314:257-61.

2 Black N, Langham S, Petticrew M. Coronary revascularisation: why do rates vary geographically in the UK? F Epidemiol Community Health 1995;49:408-12.

3 MacLeod MCM, Finlayson AR, Pell JP, et al. Geographic, demographic, and socioeconomic variations in the investigation and management of coronary heart disease in Scotgation and management of
land. Heart 1999;81:252-6.

4 Majeed FA, Cook DG. Age and sex differences in the management of ischaemic heart disease. Public Health 1996; 110:7-12.

5 Dong W, Ben-Shlomo Y, Colhoun H, et al. Gender differences in accessing cardiac surgery across England: a cross-sectional analysis of the health survey for England. Soc Sci Med 1998;47:1773-80.

6 Spencer I, Unwin N, Pledger G. Hospital investigation of men and women treated for angina. BMF 1995;310:1576.

7 Tunstall Pedoe H, Kuulasmaa K, Mahonen M, et al. Contribution of trends in survival and coronary-event rates to changes in coronary heart disease mortality: 10-year results from 37 WHO MONICA Project populations. Lancet 1999;353:1547-57.

8 Carstairs V, Morris R. Deprivation and health in Scotland. Aberdeen: Aberdeen University Press, 1991.

9 Womersley J. The public health uses of the Scottish Community Health Index (CHI). $\mathcal{F}$ Public Health Med 1996;18:465-72.

10 Rose GA, McCartney P, Reid D. Self-administration of a questionnaire on chest pain and intermittent claudication. questionnaire on chest pain and
Br f Prev Soc Med 1977;31:42-8.

11 Hobbs R Deprivation payments-still awaiting change. BMF 1993;306:534-5.

12 Hart CL, Watt GCM, Davey Smith G, et al. Pre-existing ischaemic heart disease and ischaemic heart disease mortality in women compared with men. Int $\mathcal{F}$ Epidemiol 1997;26:508-15

13 Lampe FC, Whincup PH, Wannamethee SG, et al. Chest pain on questionnaire and prediction of major ischaemic heart disease events in men. Eur Heart $\mathcal{f}$ 1998; 19:63-73.

14 Rose GA. The diagnosis of ischaemic heart pain and intermittent claudication in field surveys. Bull World Health Organ 1962;27:645-58.

15 Hlatky MA, Mark DB, Califf RM, et al. Angina, myocardial ischemia and coronary disease: gold standards, operational definitions and correlations. F Clin Epidemiol 1989;42:3814 .

16 Sullivan AK, Holdright DR., Wright CA, et al. Chest pain in women: clinical, investigative and prognostic features. BMF 1994;308:883-6.

17 Smith WCS, Kenicer MB, Tunstall Pedoe $\mathrm{H}$, et al. Smith WCS, Kenicer MB, Tunstall Pedoe H, et al.
Prevalence of coronary heart disease in Scotland: Scottish Prevalence of coronary heart disease in Scotland:

18 Hawthorne VM, Watt GCM, Hart CL, et al. . Cardiorespiratory disease in men and women in urban Scotland: baseline characteristics of the Renfrew/Paisley (MIDSPAN) Study Population. Scott Med F 1995;40:102-7.

9 Morrison C, Woodward M, Leslie W, et al. Effect of socio-economic group on incidence of, management of, and survival after myocardial infarction and coronary death: analysis of community coronary event register. BMF 1997;314:541-6.

20 Payne JN, Coy J, Milner PC, et al. Are deprivation indicators a proxy for morbidity? A comparison of the prevalence of arthritis, depression, dyspepsia, obesity and respiratory symptoms with unemployment rates and Jarman scores. $\mathcal{F}$ symptoms with unemployment rates

21 Wun YT, Chan K, Lee A. Co-morbidity in general practice. Fam Pract 1998;15:266-7.

22 Carr-Hill RA, Rice N, Roland M. Socioeconomic determinants of rates of consultation in general practice based on fourth national morbidity survey of general practices. BMF 1996;312:1008-13.

23 McKinlay JB, Potter DA, Feldman HA. Non-medical influences on medical decision-making. Soc Sci Med 1996;42: 769-76.

24 Sharp I. Attitudes to women and coronary heart disease. In: Coronary heart disease: are women special? London: National Forum for Coronary Heart Disease Prevention, 1994.

25 Griffiths F. Women's health concerns. Is the promotion of hormone replacement therapy for prevention important to women? Fam Pract 1995;12:54-9.

26 Kandrac M. Gender differences in health related behaviour: some unanswered questions. Soc Sci Med 1991;32:579-90.

7 Hibbard J, Pope $C$. Another look at sex differences in the use of medical care: illness orientation and the types of morbidities for which services are used. Women Health 1986;11:21-36.

28 Sayer GP, Britt H. Sex differences in morbidity: a case of discrimination in general practice. Soc Sci Med 1996;42: discrim

29 Lyons R, Payne C, McCabe M, et al. Legibility of doctors' handwriting: quantitative comparative study. BMF 1998; 317:863-4. 